\title{
In Silicon Design of Antimicrobial Oligopeptides Based on 3D- QSAR Modelling and Bioassay Evaluation
}

\author{
Guangping Li ( $\square$ 781885413@qq.com ) \\ Chongqing University of Technology \\ Yuxuan Wang \\ Chongqing University of Technology \\ Yan Shen \\ Chongqing University of Technology \\ Haiqiong Guo \\ Southwest University \\ Qingxiu He \\ Chongqing University of Technology \\ Yong Hu \\ Chongqing University of Technology \\ Haibin Liu \\ Chongqing University of Technology \\ Zhihua Lin \\ Chongqing University of Technology \\ Yuanqiang Wang \\ Chongqing University of Technology
}

\section{Research Article}

Keywords: 3D-QSAR, CoMFA, CoMSIA, antimicrobial peptides, S. aureus, E. coli

Posted Date: May 21st, 2021

DOI: https://doi.org/10.21203/rs.3.rs-523910/v1

License: (1) This work is licensed under a Creative Commons Attribution 4.0 International License. Read Full License 


\section{Abstract}

The emergence of multi-drug resistance bacteria poses great health theat. Therefore, it is a crucial demand to obtain new antibacterial drugs. Antimicrobial peptides (AMPs) have the characteristics of wide antimicrobial spectrum and lower drug resistance, hence, it is hopeful to substitute for classical antibiotics. In this study, two classic methods, comparative molecular field analysis (CoMFA) and comparative molecular similarity index analysis (CoMSIA), were used to analysis the structural feature of small AMPs against $S$. aureus or E. coli respectively. Subsequently, Three-Dimensional Quantitative Structure-Activity Relationships (3D-QSAR) models (for $S$. aureus, CoMFA: $Q^{2}=0.512, R^{2}=0.943, F=59.916$; CoMSIA: $Q^{2}=0.645, R^{2}=0.993, F=339.242 ;$ for $E$. Coli, CoMFA: $Q^{2}=0.507, R^{2}=$ $0.913, F=66.862$; CoMSIA: $\left.Q^{2}=0.573, R^{2}=0.966, F=96.84\right)$ with good predictability and stability were constructed. Seven novel small AMPs were designed and synthesized based on the theoretical model. The novel AMPs showed potent antibacterial activity against $S$. aureus and $E$. coli without causing host toxicity. Our findings provide a potential therapeutic option using 3D-QSAR models guiding the design and modification of novel AMPs, to address the prevalent infections caused by MDR bacterial.

\section{Introduction}

Antibiotics have been widely used for their efficiency in the prevention and treatment of bacterial infections[1] for more than 70 years. However, the frequent use of antibiotics may cause changes in bacteria, known as the antibiotic resistance, which can eliminate the effectiveness of these medications[2]. Cases are abundant, for example, the vancomycin-resistant enterococci bacteria[3], the methicillin-resistant $S$. aureus ${ }^{[4]}$, and the ampicillin-resistant $E$. coli[5]. The continuous emergence of various resistant bacteria and even super bacteria have made bacterial infectious diseases an imminent problem that needs to be solved urgently[6]. Due to the repeated occurrence of multi-drug resistant bacteria, pathogens are resistant to traditional antibiotics[7]. Therefore, it is highly necessary to develop new, effective, and safe antimicrobial drugs.

Antimicrobial peptides (AMPs) are effector molecules of the innate immune system in multicellular organisms that can resist the invasion of exogenous pathogens.[8] These substances were first discovered and studied in the natural immunity of insects around the 1980s[9-11]. AMPs can be found in various organisms such as fruit flies[12, 13], bees[14, 15], marine animals[16], and mammals[17]. So far, hundreds of AMPs have been found and they can be structurally divided into four major classes: $a$-helical, $\beta$ sheet, loop, and extended peptides[18]. Compared with traditional antibiotics, advantages of AMPs include good thermal stability, high sterilization rate, broad antimicrobial spectrum, and inhibition of fungi, parasites, and viruses growth ${ }^{13,14}$. Hence, AMPs are potentially an ideal solution to antibiotic resistance.

Traditional experimental methods for identifying antibacterial peptides from polypeptides are expensive and time-consuming[19]. In addition, the development of high-throughput proteomics had rapidly increased the number of protein and polypeptide sequences[20], which makes it even more difficult to identify the effective antimicrobial peptides from large peptide samples. An alternative solution is to use computational methods to screen and predict the active antimicrobial peptides[21,22]. Compared with traditional experimental methods, computational methods are more efficient and economical[23]. Heretofore, fruitful achievements have been made by the computational methods in the investigation of antimicrobial peptides[24].

Among the computational methods, quantitative structure-activity relationship (QSAR) models are frequently used to predict the activity and properties of an unknown set of molecules. QSAR models are, essentially, regression or classification models to link the biological activities and physicochemical properties with the molecular structures[25, 26]. In recent years, researchers have successfully applied the 3D-QSAR models, which are the extensions of traditional QSAR models by considering the 3D structures of the molecules[27], to evaluate the antibacterial activity of antimicrobial peptides and provide theoretical guidance for the synthesis of novel antimicrobial peptides[28]. Therefore, the 3D-QSAR models provided the impetus for designing a new generation of synthetic antimicrobial peptides.

In this study, we collected the molecular structures of 29 antimicrobial peptides against $S$. aureus and 30 antimicrobial peptides against E. coli from the literature. Two frequently used 3D-QSAR models (CoMFA and CoMSIA)[29] were then constructed and evaluated. Based on these validated models, seven peptides were designed, and tested their activities against $S$. aureus and $E$. coli, cytotoxicity and plasma stability. The present study can serve as the theoretical support for the future design of novel antimicrobial peptides. 


\section{Results And Discussion}

\subsection{The results of 3D-QSAR}

\subsubsection{Analysis of CoMFA models}

The CoMFA model contains two force fields: the steric field (S) and the electrostatic field (E). For both AMPs, through the computational data comparison (Supplementary Table S1 and S3), the $S+E$ field showed the best result (AMPs against $S$. aureus: $Q^{2}$ $=0.51, n p=5, R^{2}=0.943, S E E=0.102$. AMPs against $E$. coli: $Q^{2}=0.577, n p=3, R^{2}=0.913, S E E=0.099$, the related data are shown in Table 1); For the external validation peptides, AMPs against $S$. aureus: $r^{2}{ }_{\text {pred }}=0.746, S D E P_{\text {ext }}=0.471 ;$ AMPs against $E$. coli: $r^{2}$ pred $=$ $0.578, S D E P_{\text {ext }}=0.435$ ). The $Q^{2}$ for both models are above 0.5 , indicating the constructed models could be useful in predicting the antibacterial activity of the peptides. The $R^{2}$ in both models are above 0.8 , indicating that there is a strong correlation between the experimental and predicted values in the training dataset. The contribution values for the steric field were higher than the electrostatic field in each model, showing that the steric field contributed greatly. Figure $2 \mathrm{~A}$ and $3 \mathrm{~A}$ are plots of the observed (square dots) and calculated (circle dots) activity values of the peptides along with the predicted values of the 7 novel peptides (rhombus dots) of the antimicrobial peptides against $S$. aureus and E. coli. For both CoMFA models, except for a few outliers, most of the points were uniformly scattered around the curve fitting.

Table 1

Related data of the CoMFA and CoMSIA models.

\begin{tabular}{|c|c|c|c|c|c|c|c|c|c|c|c|c|c|}
\hline \multirow[t]{2}{*}{ Bacteria } & \multirow[t]{2}{*}{ Method } & \multicolumn{2}{|c|}{$\angle O O$} & \multicolumn{3}{|l|}{$P L S$} & \multicolumn{5}{|c|}{ Normalized Coefficients } & \multicolumn{2}{|c|}{$\begin{array}{l}\text { External } \\
\text { validation }\end{array}$} \\
\hline & & $n p$ & $Q^{2}$ & $R^{2}$ & SEE & $F$ & $S$ & $E$ & $H$ & $D$ & $A$ & $r_{\text {pred }}{ }^{2}$ & $S D E P_{\text {ext }}$ \\
\hline \multirow{2}{*}{$\begin{array}{l}S \text {. } \\
\text { aureus }\end{array}$} & CoMFA & 5 & 0.512 & 0.943 & 0.102 & 59.916 & 0.731 & 0.269 & & & & 0.746 & 0.471 \\
\hline & CoMSIA & 7 & 0.645 & 0.993 & 0.037 & 339.242 & 0.164 & 0.323 & 0.513 & & & 0.888 & 0.350 \\
\hline \multirow[t]{2}{*}{ E. coli } & CoMFA & 3 & 0.507 & 0.913 & 0.099 & 66.862 & 0.577 & 0.423 & & & & 0.578 & 0.435 \\
\hline & CoMSIA & 5 & 0.573 & 0.966 & 0.065 & 96.841 & & 0.316 & & 0.401 & 0.284 & 0.623 & 0.411 \\
\hline
\end{tabular}


Table 2

Observed and predicted activities of CoMFA and CoMSIA models of antimicrobial peptides against $\mathrm{S}$. aureus and E. coli.

\begin{tabular}{|c|c|c|c|c|c|c|c|c|c|}
\hline \multicolumn{5}{|c|}{ Antimicrobial peptides against $S$. aureus } & \multicolumn{5}{|c|}{ Antimicrobial peptides against $E$. coli } \\
\hline \multirow[t]{2}{*}{ No. } & \multirow[t]{2}{*}{ Peptide } & \multirow[t]{2}{*}{ Obs. } & \multicolumn{2}{|l|}{ Pred. } & \multirow[t]{2}{*}{ No. } & \multirow[t]{2}{*}{ Peptide } & \multirow[t]{2}{*}{ Obs. } & \multicolumn{2}{|l|}{ Pred. } \\
\hline & & & CoMFA & CoMSIA & & & & CoMFA & CoMSIA \\
\hline \multicolumn{10}{|c|}{ Training dataset } \\
\hline 1 & WWRWRW-NH ${ }_{2}$ & 5.33 & 5.252 & 5.311 & 1 & WRWRWR-NH ${ }_{2}$ & 5.02 & 4.96 & 5.074 \\
\hline 2 & RWWWRR-NH ${ }_{2}$ & 5.32 & 5.378 & 5.340 & 2 & RRWWCR-NH ${ }_{2}$ & 4.82 & 4.828 & 4.820 \\
\hline 3 & WRWRWR-NH 2 & 5.14 & 5.215 & 5.135 & 3 & RRWWCV-NH 2 & 4.73 & 4.665 & 4.678 \\
\hline 4 & RWRYRW-NH ${ }_{2}$ & 5.00 & 4.948 & 5.027 & 4 & YWRWRW-NH ${ }_{2}$ & 4.72 & 4.67 & 4.727 \\
\hline 5 & RRWWCR-NH ${ }_{2}$ & 4.94 & 4.957 & 4.945 & 5 & RRWWCF-NH ${ }_{2}$ & 4.69 & 4.679 & 4.653 \\
\hline 6 & WWRRRW-NH ${ }_{2}$ & 5.02 & 5.011 & 5.030 & 6 & RRWWCY-NH ${ }_{2}$ & 4.69 & 4.69 & 4.683 \\
\hline 7 & RRWWCI-NH ${ }_{2}$ & 4.81 & 4.823 & 4.827 & 7 & RRWWCL-NH ${ }_{2}$ & 4.67 & 4.607 & 4.665 \\
\hline 8 & RRWWCM-NH ${ }_{2}$ & 4.77 & 4.703 & 4.739 & 8 & RRWWCS-NH ${ }_{2}$ & 4.66 & 4.668 & 4.644 \\
\hline 9 & RRWWCS-NH ${ }_{2}$ & 4.34 & 4.309 & 4.297 & 9 & FRWWHR-NH ${ }_{2}$ & 4.63 & 4.644 & 4.606 \\
\hline 10 & RRWWCY-NH ${ }_{2}$ & 4.71 & 4.777 & 4.718 & 10 & RRWWCA-NH ${ }_{2}$ & 4.62 & 4.475 & 4.594 \\
\hline 11 & RRWWCH-NH ${ }_{2}$ & 4.56 & 4.601 & 4.580 & 11 & WWRRRW-NH ${ }_{2}$ & 4.62 & 4.551 & 4.636 \\
\hline 12 & RRRWWW-NH ${ }_{2}$ & 4.53 & 4.532 & 4.530 & 12 & RRWWCH-NH ${ }_{2}$ & 4.61 & 4.515 & 4.585 \\
\hline 13 & RRWQWR-NH ${ }_{2}$ & 4.52 & 4.467 & 4.523 & 13 & RRWWCM-NH ${ }_{2}$ & 4.59 & 4.463 & 4.546 \\
\hline 14 & RRWWCA-NH ${ }_{2}$ & 4.39 & 4.302 & 4.385 & 14 & RRWWCT-NH ${ }_{2}$ & 4.56 & 4.49 & 4.554 \\
\hline 15 & RRWWCT-NH ${ }_{2}$ & 4.35 & 4.330 & 4.368 & 15 & RRWWCI-NH ${ }_{2}$ & 4.49 & 4.449 & 4.524 \\
\hline 16 & RRWWCP-NH ${ }_{2}$ & 4.30 & 4.266 & 4.297 & 16 & RRWWCN-NH ${ }_{2}$ & 4.31 & 4.428 & 4.258 \\
\hline 17 & RRWWCG-NH ${ }_{2}$ & 4.28 & 4.222 & 4.268 & 17 & RRWWCC-NH ${ }_{2}$ & 4.19 & 4.455 & 4.424 \\
\hline 18 & RRWWCQ-NH ${ }_{2}$ & 4.11 & 4.157 & 4.094 & 18 & RRWWCD-NH ${ }_{2}$ & 3.89 & 3.921 & 3.867 \\
\hline 19 & RRWWCN-NH ${ }_{2}$ & 3.94 & 4.259 & 3.923 & 19 & RRWWCE-NH ${ }_{2}$ & 3.89 & 3.928 & 3.898 \\
\hline 20 & RRWWCW-NH ${ }_{2}$ & 4.39 & 4.275 & 4.387 & 20 & RWRWRW-NH ${ }_{2}$ & 5.32 & 5.388 & 5.306 \\
\hline 21 & YWRWRW-NH ${ }_{2}$ & 5.02 & 5.044 & 4.979 & 21 & RRWWCK-NH ${ }_{2}$ & 4.71 & 4.822 & 4.726 \\
\hline 22 & RRWWCL-NH ${ }_{2}$ & 4.84 & 4.790 & 4.784 & 22 & RKKWFW-NH ${ }_{2}$ & 4.64 & 4.698 & 4.602 \\
\hline 23 & RRWWCV-NH ${ }_{2}$ & 4.67 & 4.563 & 4.689 & 23 & RRWWCQ-NH ${ }_{2}$ & 4.37 & 4.444 & 4.37 \\
\hline 24 & RRWWCC-NH ${ }_{2}$ & 4.24 & 4.338 & 4.343 & & & & & \\
\hline \multicolumn{10}{|c|}{ Test dataset } \\
\hline 25 & RWRWRW-NH ${ }_{2}$ & 5.32 & 5.051 & 5.021 & 24 & RRRWWW-NH ${ }_{2}$ & 5.32 & 4.812 & 4.814 \\
\hline 26 & FRWLLF-NH ${ }_{2}$ & 4.92 & 4.779 & 4.901 & 25 & RRWWCG-NH ${ }_{2}$ & 4.60 & 4.571 & 4.653 \\
\hline
\end{tabular}




\begin{tabular}{|lllllllllll|}
\hline \multicolumn{7}{|c}{ Antimicrobial peptides against S. aureus } & \multicolumn{5}{c|}{ Antimicrobial peptides against E. coli } \\
\hline 27 & RRWWCF-NH & 4.92 & 4.334 & 4.597 & 26 & RWRYRW-NH & 4.31 & 4.666 & 4.716 \\
28 & RRWWCK-NH & 4.75 & 4.612 & 4.534 & 27 & RRWQWR-NH & 4.22 & 4.767 & 4.66 \\
29 & RRWWRF-NH & 5.32 & 4.637 & 4.843 & 28 & RRWWCP-NH & 4.61 & 4.467 & 4.396 \\
& & & & & 29 & RRWWRF-NH & 4.22 & 4.798 & 4.791 \\
\hline & & & & 30 & RRWWCW-NH & 4.24 & 4.554 & 4.589 \\
\hline
\end{tabular}

\subsubsection{Analysis of CoMSIA Models}

For the CoMSIA models, there are five force fields, namely electrostatic $(E)$, steric $(S)$, hydrophobic $(H)$, hydrogen bond acceptor field (A), and hydrogen bond donor field (D). In total, there are 31 CoMSIA force field combinations. Through data comparison (Supplementary table $\mathrm{S} 2$ and $\mathrm{S} 4$ ), the $\mathrm{S}+\mathrm{E}+\mathrm{H}$ fields were selected as the best field of the antimicrobial peptides against $\mathrm{S}$. aureus $\left(Q^{2}=0.645, n p=7, R^{2}=0.993, S E E=0.037, F=339.242\right)$. The contribution rates of the steric, electrostatic, and hydrophobic field are $0.164 \%, 0.323 \%$, and $0.513 \%$. For the antimicrobial peptides against $E$. coli, the CoMSIA-EDA model performs the best $\left(Q^{2}=0.573, n p\right.$ $\left.=5, R^{2}=0.966, S E E=0.065, F=96.841\right)$. The contribution rate of the electrostatic, hydrogen bond donor, and hydrogen bond acceptor field are $0.316 \%, 0.401 \%$, and $0.284 \%$ respectively, meaning that the hydrogen bond donor field contributed most in this model. The scatter plots of the CoMSIA model are shown in Fig. 2B and 3B, the alignment of the dots indicates the robustness of both models. The predictive ability of the peptides in the test set for the CoMSIA models were evaluated by the external validation method (AMPS against $S$. aureus: $r_{\text {pred }}^{2}=0.888, S D E P_{\text {ext }}=0.350$. AMPs against $E$. coli: $\left.r_{\text {pred }}^{2}=0.623, S D E P_{\text {ext }}=0.411\right)$.

\subsubsection{Analysis of the contour maps}

(a) Antimicrobial peptides against $S$. aureus.

Figure 4A and 4B are the contour maps of the steric and electrostatic fields in the CoMFA model of antimicrobial peptides against $S$. aureus. We used peptide 1 as a template to illustrate the three-dimensional contour maps of the CoMFA model. In Fig. 4A, there are yellow contours on the 1-, 3-, 4-, and 5-places of the peptide, suggesting the amino acid residues with small molecule in these regions are favorable to increase the molecule activity. Green contours can be observed on the 6-place of the peptide, indicating regions where increased steric bulk are predicted to enhance the peptide activity. This can be used to explain why peptide $1\left(\right.$ WWRWRW-NH ${ }_{2}$, consisting of a tryptophan (W) at the 6-place), has greater activity than peptide $19\left(\mathrm{RRWWCN}-\mathrm{NH}_{2}\right)$, which has an asparagine $(\mathrm{N})$ at its 6-place (the relative molecular mass of tryptophan $(\mathrm{W})$ is larger than asparagine $(\mathrm{N})$ ). In the CoMFA electrostatic contour map (Fig. 4B), red contours occur in the 1-, 2-, and 4-places of the peptide and the 5-place of the peptide chain, showing the interaction can be enhanced by negatively charged substituents at these regions. The blue contours on the 5-place of the peptide indicates that positively charged substituents in that position are favorable.

The steric, electrostatic, hydrophobic fields are used to construct the CoMSIA contours maps (Fig. 5). In Fig. 5A, the yellow contours on the 1-, 4-, and 6-places of the peptide indicate that the amino acid residues with a small molecular weight at these regions are favorable for the peptide activity. The increased peptide activity can also be contributed by large molecular weight on the 5-place of the peptide and the 6-place of the peptide near the peptide chain as shown by the green contours. In Fig. 5B, there are red areas in the $\mathrm{N}$-end and $\mathrm{C}$-end of the peptide chain, and in the 1-place of the peptide, indicating that negatively charged groups can be added here for increased peptide activity. The blue contours on the 5-and 6-place of the peptide indicate positively charged groups here were favorable. In Fig. 5C, gray areas can be mainly observed on the 1-and 4-place of the peptide, indicating that hydrophilic groups in these areas are favorable for the peptide activity while light blue region on the 6-place of the peptide means that hydrophobic groups at these regions can contribute to the enhanced activity. The difference in the antimicrobial activity of peptides 1 and 19 can also be explained by the hydrophobic tryptophan group and the hydrophilic asparagine group at the 6-place on these two peptides.

(b)Antimicrobial peptides against E. coli

Figure 6 shows the contour maps of CoMFA model (using peptide 20 as a template molecule). Figure 6 A shows the steric counter map, green areas on the 4- and 6-places of the peptide and the yellow regions observed far from the peptide chain indicate the regions 
where increased or decreased steric bulk are predicted to enhance the peptide activity. Figure $6 \mathrm{~B}$ highlights the areas where increased (red region) and decreased (blue region) electron density, respectively, can lead to the increased activity of the peptides. Taking peptide 18 (RRWWCD-NH ${ }_{2}$ ) and 24 (RRRWWW-NH ${ }_{2}$ ) in the E. coli set as an example. Aspartic (D) is a negatively charged amino acid and has a relatively smaller molecular weight locates at the 6-place of peptide 18 while tryptophan (W) is positively charged and locates at the same region of peptide 24 . In consistent with the observed value, the contour map suggests that peptide 24 has a relatively greater antimicrobial activity than peptide 18 because positively charged and large molecular weight groups at the 6-place can increase the activity of the peptide.

Figure 7 Contour maps of CoMSIA analysis in combination with compound 20. (A) Electrostatic field. Red contours mean negative charge is favorable, blue contours mean the opposite. (B) Donor field. Purple contours mean hydrogen bond donors are unfavorable, light blue mean the opposite. (C) Acceptor field. Light purple contours mean the hydrogen bond donor is unfavorable.

\subsection{Synthesis of novel peptides}

According to the established QSAR models, we designed and synthesized 7 antimicrobial peptides. After the synthesis and purification of these peptides, we found the molecular weights detected by the relative molecular mass (MS) were fully consistent with the theoretical calculations. Tested by HPLC (high performance liquid chromatography), the purities of the synthesized peptides were showed to reach more than $95 \%$. The predicted values, the purities of the 7 antimicrobial peptides, and the HPLC and MS spectra are shown in Table 2-3 and Supplementary Figure S1-S7.

Table 3

Sequence and physicochemical properties of the designed peptides

\begin{tabular}{|llllll|}
\hline NO. & Sequence & \multicolumn{2}{l}{ MS } & HPLC & Spectrogram \\
\cline { 3 - 5 } & & Calculated & Observed & Purity & \\
\hline D1 & RRWWRW-NH 2 & 1045.2 & 1044.4 & $96.76 \%$ & Figure S1 \\
\hline D2 & RRWWR-PEA & 962.2 & 962.4 & $96.28 \%$ & Figure S2 \\
\hline D3 & RRWWRW-PEA & 1148.4 & 1148.4 & $95.70 \%$ & Figure S3 \\
\hline D4 & RRFFRF-PEA & 1031.3 & 1030.8 & $98.79 \%$ & Figure S4 \\
\hline D5 & RR(BIP)(BIP)R-PEA & 1034.3 & 1.35 .0 & $98.44 \%$ & Figure S5 \\
\hline D6 & FRWWQR-NH & 978.1 & 977.6 & $99.5 \%$ & Figure S6 \\
\cline { 1 - 3 } D7 & RRQWFW-NH & 978.1 & 977.4 & $96.32 \%$ & Figure S7 \\
\hline
\end{tabular}

\subsection{Antimicrobial activity of the novel peptides}

The in vitro antimicrobial properties of 7 novel peptides were evaluated against $S$. aureus and $E$. coli. As shown in Table 4, the minimal inhibitory concentration (MIC) values of the newly designed peptides range between $8.0-64 \mu \mathrm{g} / \mathrm{mL}$. All the designed peptides showed potential antimicrobial activities. Furthermore, we analyzed the relationship between structure and antibacterial activity of these peptides. Peptides with phenylethy at the C-terminus displayed lower MIC values. The structures as well as the observed and predicted $\mathrm{plC}_{50}$ values of the novel peptides were shown in Table 5. From this table we found that there was little difference between the observed and calculated value of these seven peptides for both models. These results indicate that the two models were well constructed, providing theoretical basis and support for the design of new antimicrobial peptides.

Table 4

Antibacterial activity of antimicrobial peptides.

\begin{tabular}{|lllllllll|}
\hline Bacterial & \multicolumn{6}{c|}{ Minimal inhibitory concentrations MIC $(\mu \mathrm{g} / \mathrm{mL})$} \\
\cline { 2 - 9 } & D1 & D2 & D3 & D4 & D5 & D6 & D7 & IPM \\
\hline S. aureus & 64 & 64 & 16 & 8 & 8 & 16 & 16 & $<0.5$ \\
\hline E. coli & 64 & 64 & 16 & 32 & 16 & 16 & 16 & 4 \\
\hline
\end{tabular}


Table 5

The structure and observed/predicted pIC50 of the novel peptides.

\begin{tabular}{|c|c|c|c|c|c|c|c|}
\hline \multicolumn{5}{|c|}{ Antimicrobial peptides against $S$. aureus } & \multicolumn{3}{|c|}{ Antimicrobial peptides against $E$. coli } \\
\hline \multirow[t]{2}{*}{ NO. } & \multirow[t]{2}{*}{ Peptide } & \multirow[t]{2}{*}{ Obs. } & \multicolumn{2}{|l|}{ Pred. } & \multirow[t]{2}{*}{ Obs. } & \multicolumn{2}{|l|}{ Pred. } \\
\hline & & & CoMFA & CoMSIA & & CoMFA & CoMSIA \\
\hline D1 & RRWWRW-NH ${ }_{2}$ & 4.51 & 4.594 & 4.690 & 3.91 & 4.835 & 4.774 \\
\hline D2 & RRWWR-PEA* & 4.49 & 3.539 & 5.234 & 4.49 & 2.451 & 4.692 \\
\hline D3 & RRWWRW-PEA* & 5.10 & 3.586 & 3.947 & 5.10 & 2.493 & 4.283 \\
\hline D4 & RRFFRF-PEA* & 5.40 & 3.528 & 5.240 & 4.80 & 2.376 & 3.841 \\
\hline D5 & $\mathrm{RR}(\mathrm{BIP})^{\#}(\mathrm{BIP}) \mathrm{R}-\mathrm{PEA}{ }^{*}$ & 5.40 & 3.157 & 5.530 & 5.10 & 2.576 & 4.244 \\
\hline D6 & FRWWQR-NH ${ }_{2}$ & 4.79 & 5.054 & 5.115 & 4.79 & 4.437 & 4.565 \\
\hline D7 & RRQWFW-NH2 & 4.79 & 4.118 & 4.238 & 4.79 & 4.53 & 4.653 \\
\hline
\end{tabular}

\subsection{Plasma stability assay of the synthesized antimicrobial peptides}

A serious disadvantage of antimicrobial peptides, which hinders their practical application, is that they are susceptible to be degraded. Based on the results of plasma stability test, three novel peptides with better effects and representativeness (D1, D2, and D3) were selected for experimental research. Because sheep plasma used in the experiment was not from the same batch, the initial content of different antimicrobial peptides in plasma was quite different. The relative content of residual antimicrobial peptides in plasma at different time periods was shown in Fig. 8. The residual percentage of antimicrobial peptide RRWWRW-NH $\mathrm{N}_{2}$ in plasma at $15 \mathrm{~min}, 30$ min, 60 min, 90 min are $81.6 \%, 65.3 \%, 49.7 \%, 44.3 \%$ respectively, while the residuals of peptides D2 and D3 in plasma at 90 min are $97.4 \%, 97.6 \%$. These results indicate that peptide D1 is not stable in plasma. However, over 97\% of peptide D2 and D3 remained after 90 min of plasma incubation, indicating that these two peptides do not easily degrade in plasma and can maintain a long-term stability to exert their antimicrobial effect. Analyzing the structure of these three antimicrobial peptides, we found that the two peptides (D2 and D3) with higher stability are C-terminal phenylethylamine derivatives of antimicrobial peptide D1. For antimicrobial peptides like peptide D1, in later structure design and modification, C-terminal phenethylamine can be considered to improve the stability in plasma.

\subsection{Hemolytic toxicity test of the synthesized antimicrobial peptides}

The cytotoxicity of antimicrobial peptides in normal mammalian cells is another important feature that limits their clinical application. The cationic antimicrobial peptide works by electrostatically attracting the negatively charged phosphatidylglycerol and cardiolipin in the bacterial cell membrane to destroy the bacterial cell membrane structure[30]. However, the cytomembrane of eukaryotic cell also contains a small amount of negatively charged phospholipids (such as phosphatidylserine and phosphatidylinositol), which may cause the combination of antimicrobial peptides and eukaryotic cell membranes and thus causing cytotoxicity[31]. To determine the cytotoxicity of these novel peptides, the hemolytic activity of these peptides against sheep red blood cells was measured. As shown in Fig. 9, peptides D1 and D2 were not toxic to red blood cells. The hemolytic activity of red blood cells at the concentration of 512 $\mu \mathrm{g} / \mathrm{mL}$ are $2.50 \%$ and $4.33 \%$ (<10\%). For peptide D3, hemolytic activity of red blood cells at the concentration of $64 \mu \mathrm{g} / \mathrm{mL}$ is $5.05 \%$. However, when the concentration reaches $128 \mu \mathrm{g} / \mathrm{mL}$, the hemolytic activity is $22.88 \%$. Further modifications should be made on this peptide to decrease host toxicity.

\section{Conclusion}


In this study, we first used SYBYL to establish the CoMFA and CoMSIA models to study the three-dimensional quantitative structureactivity relationship of 29 antimicrobial peptides against $S$. aureus and 30 antimicrobial peptides against $E$. coli extracted from the literature. The $Q^{2}$ and $R^{2}$ values indicate that these models are well-established for both two antimicrobial peptides. The contour maps of the model visually reflect the structure-activity relationship of peptides. Based on these models, we designed and synthesized 7 antimicrobial peptides and predicted their activity values. We then experimentally validated that these 7 peptides have certain antibacterial activity against gram-positive bacterium (S. aureus) and gram-negative bacterium (E. coli) with good purity, stability, and low toxicity. Our results indicate that the well-constructed 3D-QSAR models can provide important theoretical basis for the design, modification and synthesis of the new antimicrobial peptides.

\title{
4 Materials And Methods
}

\subsection{Data sources}

Molecular structures of 29 antimicrobial peptides against $S$. aureus and 30 antimicrobial peptides against $E$. coli and their minimum inhibitory concentration (MIC) were extracted from literatures[32-42, 30, 43]\{Sundriyal, 2008 \#36;Strøm, 2002 \#37;Liu, 2007 \#41\} \{Murugan, 2013 \#39;Albada, 2012 \#40;Liu, 2007 \#41\}. The inhibitory effect of these peptides on S. aureus and E. coli were expressed as $\mathrm{plC}_{50}\left(\mathrm{plC}_{50}=-\log \mathrm{IC}_{50}\right)$. The dataset was randomly divided into training sets ( 24 antimicrobial peptides against $S$. aureus and 23 antimicrobial peptides against $E$. coli) and test sets ( 5 antimicrobial peptides against $S$. aureus and 7 antimicrobial peptides against E. coli).

\subsection{Molecular construction and optimization}

The 3D structures of all peptides in the training and test sets were constructed using SYBYL 2.1.1. The Gasteiger-Hückel charge[44] was used to calculate the peptides' charges. The energy minimizations were conducted using the Tripos force field[45] with the max iterations of 1000 and the gradient was $0.005 \mathrm{kcal} /(\mathrm{mol} \AA$ ). Conformation with the lowest energy was selected as the active conformation. The 'align database' command in SYBYL was used for superimposing the collected AMPs. The optimized peptides with the maximum activity (lowest energy) were selected as the template for superimposition. The alignments of antimicrobial peptides are shown in Figure1.

\subsection{CoMFA and CoMSIA modeling}

As classic methods, CoMFA and CoMSIA models are widely used in 3D-QSAR studies. CoMFA and CoMSIA models can reflect the activity of the compounds through 2 fields (electrostatic and steric field)[46] and 5 fields (electrostatic, steric, hydrophobic, hydrogen bond acceptor field and donor field)[47] respectively. The partial least square (PLS) models[48] were derived to analyze the extension of the multiple regression. Cross-validation was performed by the leave-one-out method (LOO)[49] to calculate $Q^{2}$ and get the optimum number of components $(n p)$. The non-cross-validated correlation coefficient $\left(R^{2}\right), F$ values and error of estimate (SEE) of the model were calculated to evaluate the reliability and predictivity ability of the models[50]. The external prediction ability of the model was evaluated by the predicted $r^{2}\left(r^{2}\right.$ pred $\left.>0.5\right)$ and external standard deviation error of prediction $\left(S D E P_{\text {ext }}\right)$ using the following equations[51]:

$$
\begin{aligned}
& r_{\text {pred }}^{2}=1-\frac{\sum_{1}^{n_{\text {ext }}}\left(y_{i}-\hat{y}_{i}\right)^{2}}{\sum_{1}^{n_{\text {ext }}}\left(y_{i}-\overline{\bar{y}}_{i}\right)^{2}} \\
& S D E P=\sqrt{\frac{\sum_{1}^{n_{\text {ext }}}\left(y_{i}-\hat{y}_{i}\right)^{2}}{n_{\text {ext }}}}
\end{aligned}
$$

where the $y_{i}$ and $\hat{y}_{i}$ represents the observed and calculated values, $\bar{y}_{i}$ is the average of the observed value in the training set, $n_{\text {ext }}$ represents the number of the test set.

\subsection{Synthesis of novel antimicrobial peptides}

\author{
Page $8 / 15$
}


According to the models, 7 new peptides were designed. The novel peptides were synthesized under the solid-phase synthesis method as described[52]. Briefly, the dichloro resin was taken as the carrier in general, wherein halogen chlorine stays at the active site. The resin needs to be dissolved first. Then, the C-end carboxyl of the first amino acid reacts with the active site chlorine on resin. After the first amino acid was connected to resin, it is connected to the second amino acid after dehydration condensation. After that, Fmoc protection was conducted. Operations were repeated according to the designed amino acid sequence, the rest amino acids were connected in sequence, and acetylation of $\mathrm{N}$-end was completed. Finally, the polypeptide was cut from resin with a cutting reagent[53, 54] and the naked carboxyl was formed.

\subsection{Antimicrobial activity assay}

Minimal inhibitory concentration (MIC) of each peptide against gram-positive bacterium (S. aureus) and gram-negative bacterium (E. coli) was determined using the broth micorodilution assay as described with slight modification[55]. Briefly, mid-logarithmic phase cells were diluted to $2.0 \times 10^{5} \mathrm{CFU} / \mathrm{mL}$ in Mueller-Hinton Broth growth medium. $50 \mu \mathrm{l}$ of the diluted cell suspension were mixed in 96well plates with $50 \mu$ peptide in PBS solution at different stock concentrations $(2-512 \mu \mathrm{g} / \mathrm{mL})$. The suspensions were then incubated at $37^{\circ} \mathrm{C}$ for $12 \mathrm{~h}$. The growth of bacteria was determined by measuring the absorbance at $600 \mathrm{~nm}$ using a microplate reader. MIC was defined as the lowest concentration of investigated peptide that completely inhibited bacteria growth.

\subsection{Haemolysis assay}

The haemolytic activity of each peptide was determined as described with slight modification [56]. Briefly, fresh sheep RBCs were washed 3 times with nomal saline, then re-suspended into the $3 \%$ red cell suspension. $100 \mu \mathrm{L}$ sheep red blood cell suspension was incubated with $100 \mu \mathrm{L}$ peptide solutions at different concentrations ranging from 2 to $512 \mu \mathrm{g} / \mathrm{mL}$. Sheep red blood cells suspended in normal saline alone were used as negative control, while cells lysed with $0.1 \%$ Triton-X100 were taken as positive control. After incubation for $0.5 \mathrm{~h}$ at $37^{\circ} \mathrm{C}$, the suspension was centrifuged at $3000 \mathrm{rpm}$ for $10 \mathrm{~min} .100 \mu \mathrm{L}$ supernatant was added to 96 -well plates and absorbance was recorded at $570 \mathrm{~nm}$. The experiment was repeated 3 times and the hemolysis ratio was an average value based on the result of three repeats. Hemolysis ratio ${ }^{[57]}=\left[\left(\mathrm{OD}_{\text {test hole }}-\mathrm{OD}_{\text {negative hole }}\right) /\left(\mathrm{OD}_{\text {positive hole }}-\mathrm{OD}_{\text {negative hole }}\right)\right] \times 100 \%$.

\subsubsection{Plasma stability assay}

$25 \%$ of sheep plasma was incubated at $37^{\circ} \mathrm{C}$ for $30 \min .250 \mu \mathrm{L}$ sheep plasma was mixed with $50 \mu \mathrm{L}$ peptide solution at a concentration of $1 \mathrm{mg} / \mathrm{mL}$. The mixture was incubated in a biochemical incubator, shaking at $100 \mathrm{rpm}$ at $37^{\circ} \mathrm{C}$. After incubation for 0 , $10,30,60$, and $90 \mathrm{~min}, 200 \mu \mathrm{L}$ TFA was added to stop the reaction of peptide in plasma. The mixture was cooled for $30 \mathrm{~min}$ at $4^{\circ} \mathrm{C}$ and then centrifuged at $1200 \mathrm{rpm}$ for $30 \mathrm{~min} .200 \mathrm{uL}$ supernatant was extracted and analyzed using HPLC-QqQ-MS[58]. The 135V electrospray ionization source was used for scanning.

\section{Declarations}

\section{Acknowledgements}

Authors thank the financial support from National Natural Science Foundation of China (31400667), Scientific and Technological Research Program of Chongqing Municipal Education Commission (KJ1400932, KJ1500902, KJ1600908), Chongqing Research Program of Basic Research and Frontier Technology (cstc2014jcyjA10044, cstc2013jcyjA10019) and Program for Innovation Team Building at Institutions of Higher Education in Chongqing (CXTDX201601031). Authors would like to acknowledge the funding support to the Xie laboratory from the NIH NIDA (P30 DA035778A1).

\section{Conflict of interest}

No conflict of interest exits in the submission of this paper, and paper is approved by all authors for publication. I would like to declare on behalf of my co-authors that the work described was original research that has not been published previously, and not under consideration for publication elsewhere, in whole or in part.

Page 9/15 


\section{References}

1. Kümmerer K (2009) Antibiotics in the aquatic environment - A review - Part I. Chemosphere 75(4):417-434. doi:https://doi.org/10.1016/j.chemosphere.2008.11.086

2. Levy SB, Marshall B (2007) Antibacterial resistance worldwide: causes, challenges and responses. Nat Med Suppl 10(12 Suppl):S122

3. Murray BE (2000) Vancomycin-Resistant Enterococcal Infections. N Engl J Med 342(10):710-721. doi:10.1056/nejm200003093421007

4. Panlilio AL, Culver DH, Gaynes RP, Banerjee S, Henderson TS, Tolson JS et al (1992) Methicillin-Resistant Staphylococcus aureus in U.S. Hospitals, 1975-1991. Infection Control Hospital Epidemiology 13(10):582-586. doi:10.2307/30148460

5. Emsley P, Cowtan K (2004) Coot: model-building tools for molecular graphics. Acta Crystallogr D Biol Crystallogr 60(1):21262132. doi:10.1107/S0907444904019158. (Pt 12 Pt

6. Yong DG, Toleman MA, Giske CG, Cho HS, Sundman K, Kyungwon L et al (2009) Characterization of a new metallo- $\beta$-lactamase gene, blaNDM-1, and a novel erythromycin esterase gene carried on a unique genetic structure in Klebsiella pneumoniae sequence type 14 from India. Antimicrob Agents Chemother 53(12):5046-5054

7. Riedl S, Zweytick D, Lohner K (2011) Membrane-active host defense peptides - Challenges and perspectives for the development of novel anticancer drugs. Chemistry Physics of Lipids 164(8):766-781

8. Koczulla AR, Bals DR. Antimicrobial Peptides (2003) Drugs 63(4):389-406

9. Bakula M (1970) Antibacterial compounds in the cell-free haemolymph of Drosophila melanogaster. J Insect Physiol 16(1):185197

10. Hink WF, Briggs JD (1968) Bactericidal factors in haemolymph from normal and immune wax moth larvae, Galleria mellonella. J Insect Physiol 14(7):1025-1034

11. Steiner H, Hultmark D, Engström A, Bennich H, Boman HG (1981) Sequence and specificity of two antibacterial proteins involved in insect immunity. Nature 292: 246-248. Journal of Immunology. 2009;182(11):6635

12. Samakovlis C, Kylsten P, Kimbrell DA, Engström A, Hultmark D (1991) The andropin gene and its product, a male-specific antibacterial peptide in Drosophila melanogaster. Embo Journal 10(1):163

13. Bulet P, Dimarcq JL, Hetru C, Lagueux M, Charlet M, Hegy G et al (1993) A novel inducible antibacterial peptide of Drosophila carries an O-glycosylated substitution. J Biol Chem 268(20):14893-14897

14. Casteels P, Ampe C, Riviere L, Damme JV, Elicone C, Fleming M et al (1990) Isolation and characterization of abaecin, a major antibacterial response peptide in the honeybee (Apis mellifera). Febs Journal 187(2):381

15. Casteels P, Ampe C, Jacobs F, Vaeck M, Tempst P (1989) Apidaecins: antibacterial peptides from honeybees. Embo Journal 8(8):2387

16. Rameshkumar G, Ravichandran S, Kaliyavarathan G, Ajithkumar T (2009) Antimicrobial peptide from the crab, Thalamita crenata (Latreille, 1829). World J Fish Mar Sci 1(2):74-79

17. Lehrer RI, Ganz T (1999) Antimicrobial peptides in mammalian and insect host defence. Curr Opin Immunol 11(1):23-27. doi:https://doi.org/10.1016/S0952-7915(99)80005-3

18. Y P, KS H. Antimicrobial peptides (AMPs): peptide structure and mode of action. Journal of Biochemistry and Molecular Biology. 2005;38(5):507

19. Da CN, Cobacho NB, Viana JF, Lima LA, Sampaio KB, Dohms SS et al (2017) The next generation of antimicrobial peptides (AMPs) as molecular therapeutic tools for the treatment of diseases with social and economic impacts. Drug Discovery Today 22(2):234-248

20. Bae JS, Jeong JM, Nam BH, Kim JW, Park JY, Park Cl. Gene expressions and biological activities of two novel antimicrobial peptides (AMPs) isolated from leucocytes of the rock bream, Oplegnathus fasciatus. Aquaculture. 2018;495

21. Gautam A, Sharma A, Jaiswal S, Fatma S, Arora V, Iquebal MA et al (2016) Development of Antimicrobial Peptide Prediction Tool for Aquaculture Industries. Probiotics Antimicrob Proteins 8(3):1-9

22. Fjell C, Jenssen H, Hilpert K, Cheung W, Pante N, Hancock R et al (2009) Identification of Novel Antibacterial Peptides by Chemoinformatics and Machine Learning. J Med Chem 52(7):2006-2015 
23. Liu S, Fan L, Sun J, Lao X, Zheng H (2017) Computational resources and tools for antimicrobial peptides. J Pept Sci 23(1):4-12

24. Bolintineanu DS, Kaznessis YN (2011) Computational studies of protegrin antimicrobial peptides: A review. Peptides 32(1):188201. doi:https://doi.org/10.1016/j.peptides.2010.10.006

25. Tong JB, Jiang GY, Yuan-Yuan LI, Kang-Nan LI. 3D-QSAR study on antimicrobial peptides by CoMFA method. Journal of Atomic \& Molecular Physics. 2017

26. Chen B, Zhang T, Bond T, Gan Y (2015) Development of quantitative structure activity relationship (QSAR) model for disinfection byproduct (DBP) research: A review of methods and resources. J Hazard Mater 299:260-279.

doi:https://doi.org/10.1016/j.jhazmat.2015.06.054

27. Jitender V, Vijay MK, Evans CC (2010) 3D-QSAR in Drug Design - A Review. Curr Top Med Chem 10(1):95-115. doi:http://dx.doi.org/10.2174/156802610790232260

28. Liu S, Bao J, Lao X, Zheng H. Novel 3D Structure Based Model for Activity Prediction and Design of Antimicrobial Peptides. Scientific Reports. 2018;8

29. Bordás B, Kőmíves T, Lopata A (2003) Ligand-based computer-aided pesticide design. A review of applications of the CoMFA and CoMSIA methodologies. Pest Manag Sci 59(4):393-400. doi:10.1002/ps.614

30. Hancock RE (2001) Cationic peptides: effectors in innate immunity and novel antimicrobials. Lancet Infectious Diseases 1(3):156

31. Huang Y, Huang J, Chen Y (2010) Alpha-helical cationic antimicrobial peptides: relationships of structure and function. Protein Cell 1(2):143-152. doi:10.1007/s13238-010-0004-3

32. Sundriyal S, Sharma RK, Jain R, Bharatam PV (2008) Minimum requirements of hydrophobic and hydrophilic features in cationic peptide antibiotics (CPAs): pharmacophore generation and validation with cationic steroid antibiotics (CSAs). J Mol Model 14(4):265-278

33. Strøm MB, Rekdal O, Svendsen JS (2002) Antimicrobial activity of short arginine- and tryptophan-rich peptides. J Pept Sci 8(8):431-437

34. Strøm MB, Haug BE, Skar ML, Stensen W, Stiberg T, Svendsen JS (2003) The pharmacophore of short cationic antibacterial peptides. J Med Chem 46(9):1567-1570

35. Murugan RN, Jacob B, Kim EH, Ahn M, Sohn H, Seo JH et al (2013) Non hemolytic short peptidomimetics as a new class of potent and broad-spectrum antimicrobial agents. Bioorg Med Chem Lett 23(16):4633-4636

36. Albada HB, Prochnow P, Bobersky S, Langklotz S, Schriek P, Bandow JE et al (2012) Tuning the Activity of a Short Arg-Trp Antimicrobial Peptide by Lipidation of a C- or N-Terminal Lysine Side-Chain. Acs Medicinal Chemistry Letters 3(12):980

37. Liu Z, Brady A, Young A, Rasimick B, Chen K, Zhou C et al (2007) Length effects in antimicrobial peptides of the (RW)n series. Antimicrobial Agents Chemotherapy 51(2):597-603

38. Chou S, Shao C, Wang J, Shan A, Xu L, Dong N et al (2015) Short, multiple-stranded $\beta$-hairpin peptides have antimicrobial potency with high selectivity and salt resistance. Acta Biomater 30:78-93

39. Lee SH, Kim SJ, Lee YS, Song MD, Kim IH, Won HS (2011) De novo generation of short antimicrobial peptides with simple amino acid composition. Regul Pept 166(1):36-41

40. Muñoz A, López-García B, Marcos JF (2007) Comparative study of antimicrobial peptides to control citrus postharvest decay caused by Penicillium digitatum. Journal of Agricultural Food Chemistry 55(20):8170

41. Blondelle SE, Lohner K (2015) Combinatorial libraries: a tool to design antimicrobial and antifungal peptide analogues having lytic specificities for structure-activity relationship studies. Pept Sci 55(1):74-87

42. Giménez D, Andreu C, MI DO, Varea T, Diaz D, Asensio G (2006) The introduction of fluorine atoms or trifluoromethyl groups in short cationic peptides enhances their antimicrobial activity. Bioorg Med Chem 14(20):6971-6978

43. Remuzgo C, Oewel TS, Daffre S, Lopes TRS, Dyszy FH, Schreier S et al (2014) Chemical synthesis, structure-activity relationship, and properties of shepherin I: a fungicidal peptide enriched in glycine-glycine-histidine motifs. Amino Acids 46(11):2573-2586

44. Tsai K-C, Chen Y-C, Hsiao N-W, Wang C-L, Lin C-L, Lee Y-C et al (2010) A comparison of different electrostatic potentials on prediction accuracy in CoMFA and CoMSIA studies. Eur J Med Chem 45(4):1544-1551.

doi:https://doi.org/10.1016/j.ejmech.2009.12.063

45. Clark M, Cramer RD III, Van Opdenbosch N (1989) Validation of the general purpose Tripos 5.2 force field. J Comput Chem 10(8):982-1012 
46. Kim KH, Greco G, Novellino E (1998) A critical review of recent CoMFA applications. 3D QSAR in drug design. Springer, pp 257315

47. Ghaleb A, Aouidate A, Ghamali M, Sbai A, Bouachrine M, Lakhlifi T (2017) 3D-QSAR modeling and molecular docking studies on a series of 2,5 disubstituted 1,3,4-oxadiazoles. J Mol Struct 1145:278-284. doi:https://doi.org/10.1016/j.molstruc.2017.05.065

48. Abdi H. Partial least square regression (PLS regression). Encyclopedia for research methods for the social sciences. 2003;6(4):792-5

49. BURMAN P, CHOW E (1994) NOLAN D. A cross-validatory method for dependent data. Biometrika 81(2):351-358. doi:10.1093/biomet/81.2.351

50. Depriest SA, Mayer D, Naylor CB, Marshall GR (1993) 3D-QSAR of angiotensin-converting enzyme and thermolysin inhibitors: a comparison of CoMFA models based on deduced and experimentally determined active site geometries. J Am Chem Soc 115(13):5372-5384

51. Tosco P, Balle T (2012) A 3D-QSAR-Driven Approach to Binding Mode and Affinity Prediction. J Chem Inf Model 52(2):302-307. doi:10.1021/ci200411s

52. Chan WC, White PD. Fmoc Solid Phase Peptide Synthesis: A Practical Approach, Vol. 222. 2000

53. Montanya E (2012) A comparison of currently available GLP-1 receptor agonists for the treatment of type 2 diabetes. Expert Opin Pharmacother 13(10):1451-1467

54. Bechinger B, Gorr SU (2017) Antimicrobial Peptides: Mechanisms of Action and Resistance. J Dent Res 96(3):0022034516679973

55. Weseler A, Geiss HK, Saller R, Reichling JJDP. A novel colorimetric broth microdilution method to determine the minimum inhibitory concentration (MIC) of antibiotics and essential oils against Helicobacter pylori. 2005

56. Gauthier C, Legault J, Girard-Lalancette K, Mshvildadze V, Pichette AJB, chemistry m. Haemolytic activity, cytotoxicity and membrane cell permeabilization of semi-synthetic and natural lupane- and oleanane-type saponins. 2009;17(5):2002-8

57. Hou F, Li J, Pan P, Xu J, Liu L, Liu W et al (2011) Isolation and characterisation of a new antimicrobial peptide from the skin of Xenopus laevis. Int J Antimicrob Agents 38(6):510-515

58. Yost RA, Enke CG (1979) Triple quadrupole mass spectrometry for direct mixture analysis and structure elucidation. Anal Chem 51(12):1251-1264. doi:10.1021/ac50048a002

\section{Figures}
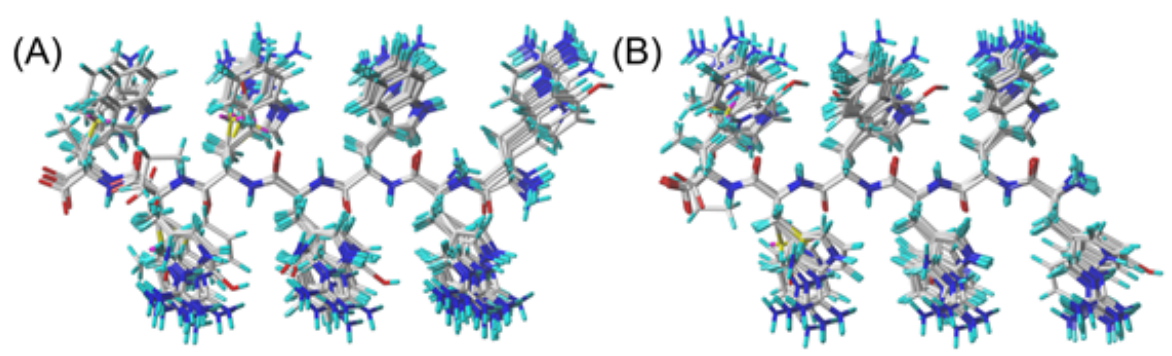

\section{Figure 1}

The Alignments of antimicrobial peptide. (A) antimicrobial peptides against S. aureus. (B) antimicrobial peptides against E. coli.
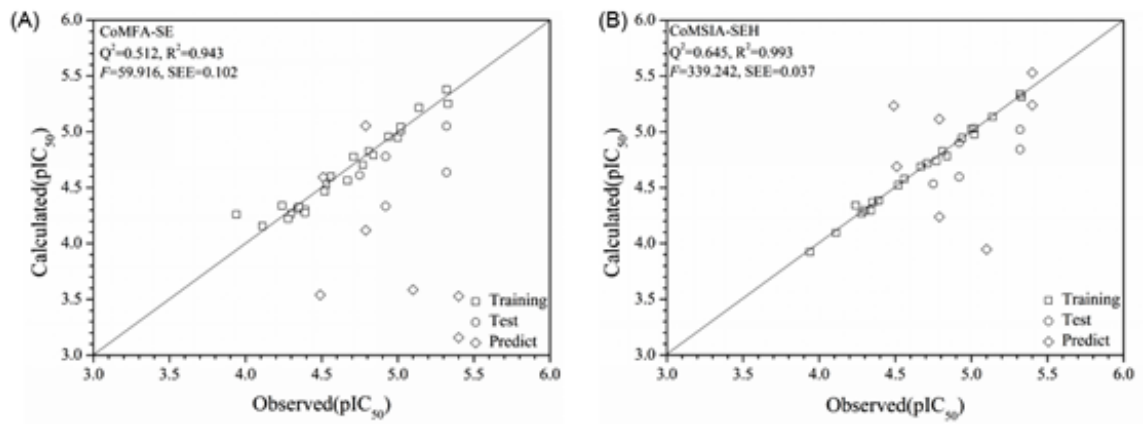

Page $12 / 15$ 


\section{Figure 2}

The plots of observed and calculated value of the peptides, together with the predicted value of the 7 novel peptides of the antimicrobial peptides against $\mathrm{S}$. aureus.
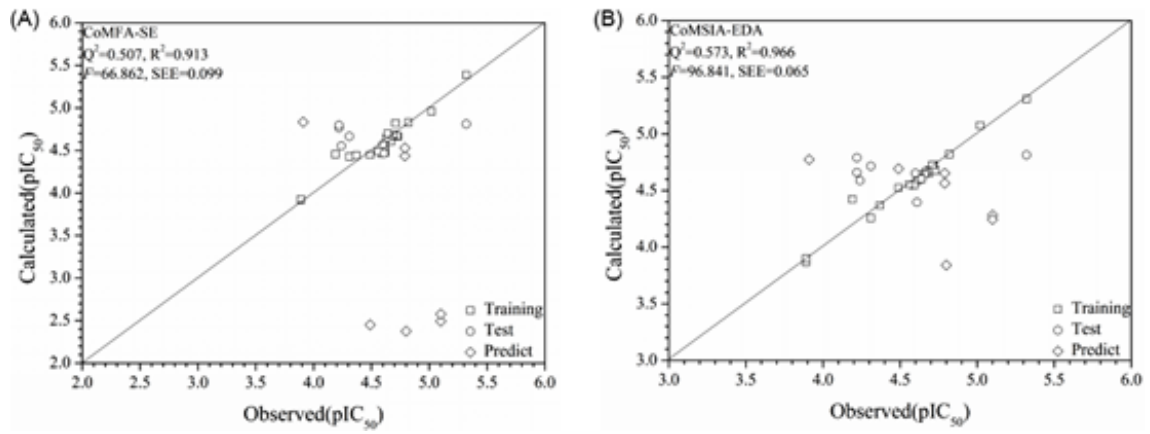

\section{Figure 3}

The plots of observed and calculated value of the peptides, together with the predicted value of the 7 novel peptides of the antimicrobial peptides against E. coli.

(A)

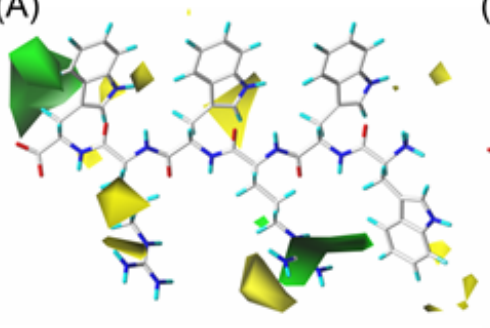

(B)

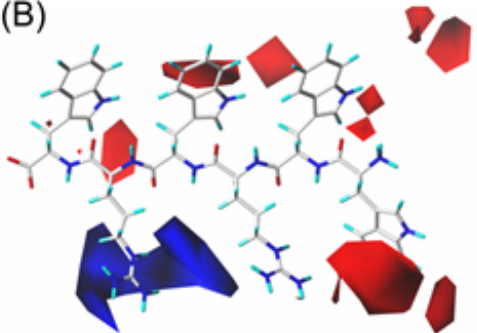

Figure 4

Contour maps of CoMFA analysis in combination with peptide 1 (A) Steric field. Green contours indicate sterically bulky groups are favorable, yellow contours indicates the opposite. (B) Electrostatic field. Red contours indicate negative charge is favorable, blue contours indicate the opposite.

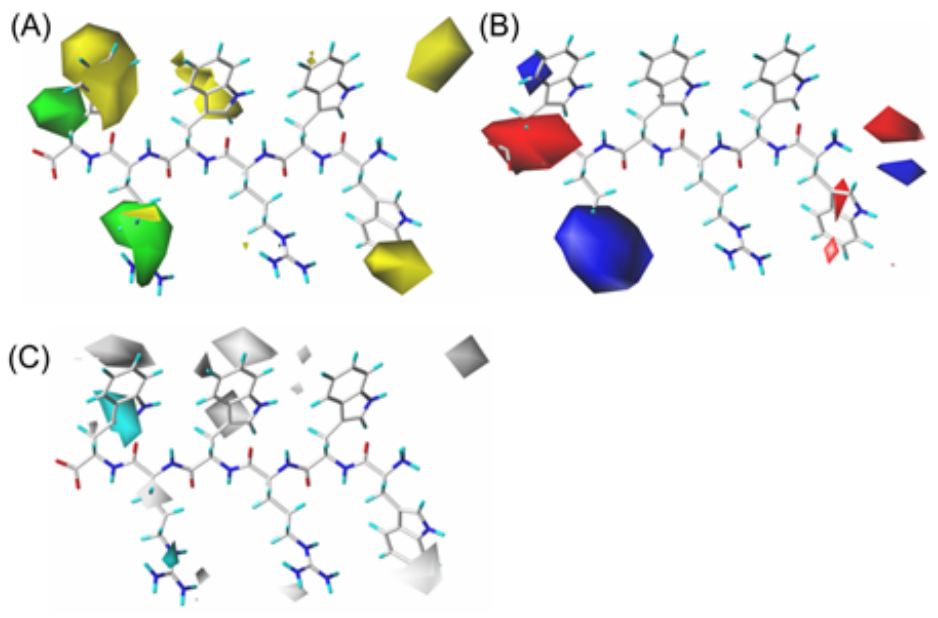

\section{Figure 5}

Contour maps of CoMSIA analysis in combination with peptide 1. (A) Steric field. Green contours meant Sterically bulky groups is favorable, yellow contours means the opposite. (B) Electrostatic field. Red contours mean negative charge is favorable, blue contours means the opposite. (C) Hydrophobic field. Gray contours mean hydrophilic groups is favorable, color light blue means that hydrophobic group was favorable. 
(A)

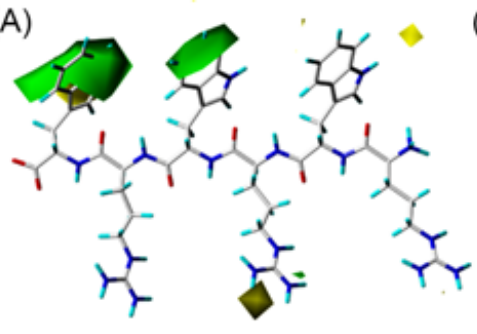

(B)

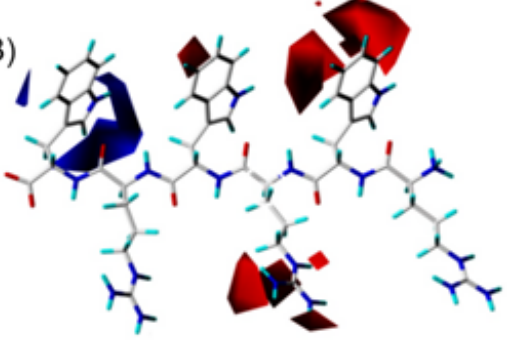

Figure 6

Contour maps of CoMFA analysis in combination with peptide 20. (A) Steric field. Green contours mean sterically bulky groups is favorable, yellow contours mean the opposite. (B) Electrostatic field. Red contours mean negative charge is favorable, blue contours mean the opposite.

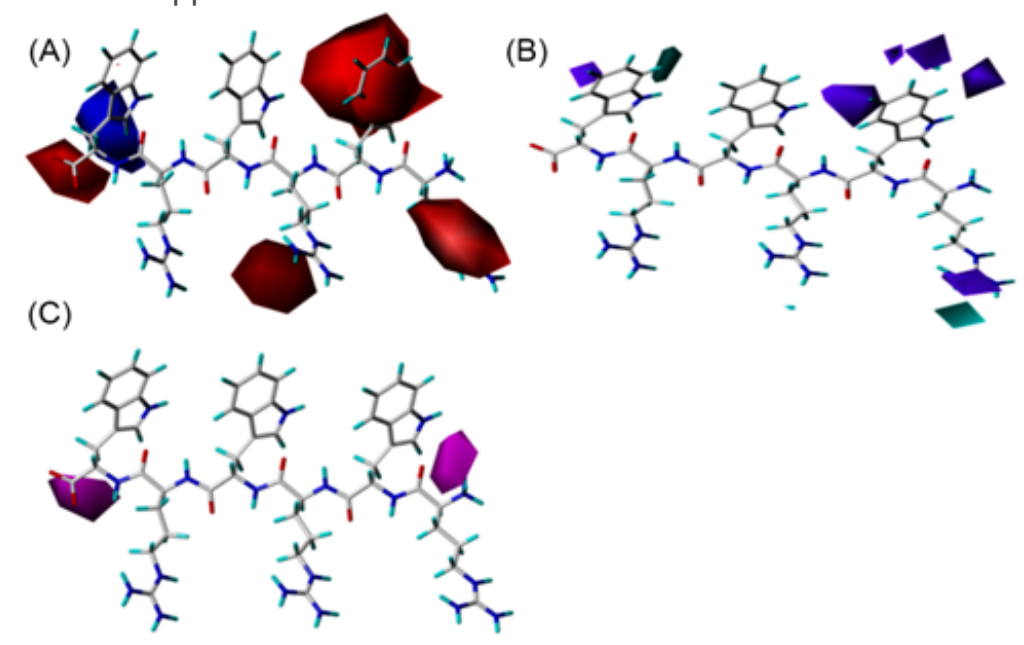

Figure 7

Contour maps of CoMSIA analysis in combination with compound 20. (A) Electrostatic field. Red contours mean negative charge is favorable, blue contours mean the opposite. (B) Donor field. Purple contours mean hydrogen bond donors are unfavorable, light blue mean the opposite. (C) Acceptor field. Light purple contours mean the hydrogen bond donor is unfavorable.

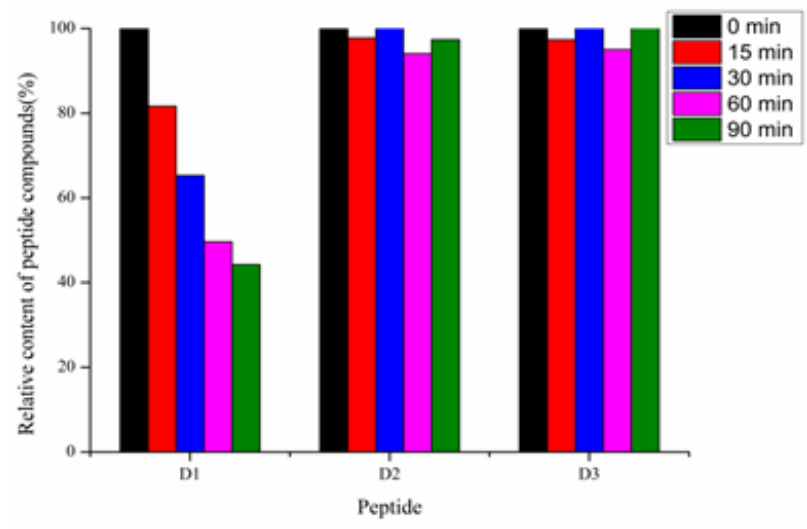

Figure 8

Stability of antimicrobial peptides in sheep plasma 


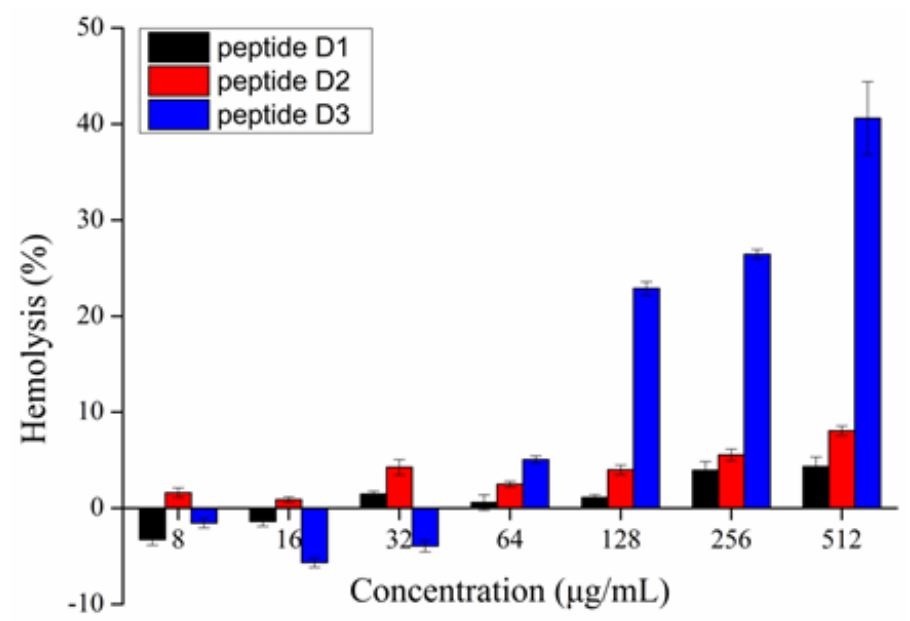

Figure 9

Hemolytic toxicity of antimicrobial peptides in vitro

\section{Supplementary Files}

This is a list of supplementary files associated with this preprint. Click to download.

- GraphicAbstract.docx

- supplementmaterial.docx 